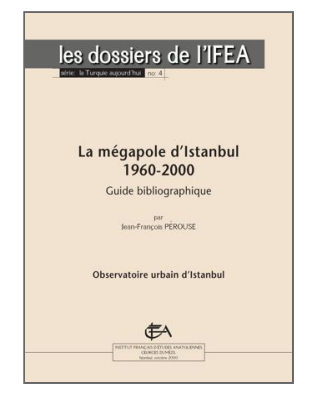

Jean-François Pérouse

La mégapole d'Istanbul 1960-2000

Guide bibliographique

Institut français d'études anatoliennes

\title{
6) L'orientation administrative, politique et géopolitique
}

DOI : 10.4000/books.ifeagd.533

Éditeur : Institut français d'études anatoliennes

Lieu d'édition : Istanbul

Année d'édition : 2000

Date de mise en ligne : 4 novembre 2014

Collection : La Turquie aujourd'hui

ISBN électronique : 9782362450181

\section{Q boOKS}

http://books.openedition.org

Édition imprimée

Date de publication : 1 octobre 2000

\section{Référence électronique}

PÉROUSE, Jean-François. 6) L'orientation administrative, politique et géopolitique In : La mégapole d'Istanbul 1960-2000 : Guide bibliographique [en ligne]. Istanbul : Institut français d'études anatoliennes, 2000 (généré le 12 janvier 2021). Disponible sur Internet : <http://books.openedition.org/ifeagd/533>. ISBN : 9782362450181. DOI : https://doi.org/10.4000/books.ifeagd.533. 


\section{6) L'orientation administrative, politique et géopolitique}

1 Alada A (s.d.) «Demokratikleşme Sürecinin Dalgalanmaları. Cumhuriyet Döneminde İstanbul'un Yönetimi », İstanbul Dergisi, « İstanbul Nasıl Yönetilmeli ? », pp. 133-138.

2 Algin Ü. (1980), Bölgemiz Marmara, İstanbul ve İlçeleri (notre région la Marmara, Istanbul et ses arrondissements), İstanbul, Birsen Kitabevi Yay., $3^{\circ}$ éd., 142 p. (IFEA : 1st. 55)

3 Alpöge A. (s.d.), « Halka Dönük Yerel Yönetim », Iula-Emme \& T.C.Başbakanlık Toplu Konut İdaresi Başkanlığı, İstanbul, $\mathrm{n}^{\circ}$ 11, 165 p.

4 Atabek D. E. et alii (1988), "Yerel Yönetimler ve Kent Sorunları », (administrations locales et questions urbaines), Bilim ve Sanat, $\mathrm{n}^{\circ}$ 93, 1988.

5 Bayraktaroğlu M. A (1987), An Analysis on Istanbul District Municipalities, thèse (MA), BÜ, Institute of Social Sciences, $57 \mathrm{p}$.

6 Bayramoğlu Alada A. (s.d.), "Yerel Yönetim ve Ahlâk », Iula-Emme \& T.C.Başbakanlık Toplu Konut İdaresi Başkanlığı, İstanbul, n 10, 109 p.

7 Bayramoğlu Yıldırım F. (s. d), « Çevre ve Yerel Yönetim », Iula-Emme \& T.C.Başbakanlık Toplu Konut İdaresi Başkanlığı, İstanbul, $\mathrm{n}^{\circ}$ 4, 108 p.

8 Bayramoğlu Yıldırım F. (s. d), « İnsan Kaynağı Yönetimi », Iula-Emme \& T.C.Başbakanlık Toplu Konut İdaresi Başkanlı̆̆ı, İstanbul, n 7, 93 p.

9 «Başkent: Ankara mı İstanbul mu? », (la capitale : c'est Ankara ou c'est Istanbul ?), Aydınlık, 21 juin 1993, supplément « Bilim ve Ütopya », p. 12.

101999 yatırım programı, İstanbul Büyükşehir Belediyesi, 1998, 195 p. (OUI)

11 Eddison T. \& Tikiz C. (s.d.), « Yerel Yönetimde Denetim », Iula-Emme \& T.C.Başbakanlık Toplu Konut İdaresi Başkanlığı, İstanbul, n 13, 108 p.

12 Eliçin-Arikan Y. (1997), «Municipalités métropolitaines et d'arrondissement en Turquie ", Cahiers d'Études sur la Méditerranée et le monde turco- iranien, $\mathrm{n}^{\circ} 24$, juillet-déc. 1997, pp. 71-104. 
Emrealp S. (s.d.), « Kriz Yönetimi, Belediyelerde », Iula-Emme \& T.C.Başbakanlık Toplu Konut İdaresi Başkanlığı, İstanbul, $\mathrm{n}^{\circ}$ 5, 92 p.

Emrealp S. \& Horgan D. (s.d.), « Alternatif Hizmet Sunma Yöntemleri, Belediyelerde », Iula-Emme \& T.C.Başbakanlık Toplu Konut İdaresi Başkanlığı, İstanbul, nº 6, 74 p.

Emrealp S. (s.d.), « Mali Yönetim, Belediyelerde », Iula-Emme \& T.C.Başbakanlık Toplu Konut İdaresi Başkanlığı, İstanbul, $\mathrm{n}^{\circ} 2,84 \mathrm{p}$.

Emrealp S. (s.d.), « Proje Yönetimi, Belediyelerde », Iula-Emme \& T.C.Başbakanlık Toplu Konut İdaresi Başkanlı̆̆

Emrealp S. (s.d.), «Bilgi Teknolojisi, Yerel Yönetim », Iula-Emme \& T.C.Başbakanlık Toplu Konut İdaresi Başkanlığı, İstanbul, $\mathrm{n}^{\circ} 12,116$ p.

Geray C. (1984), « Boğaziçi Yasası », (la loi sur le Bosphore) Mimarlık, n 1, pp. 43-45.

Heper M. (1979-80), «Recent Instability in Turkish Policies: End of a Monocentrist Policy? ", International Journal of Turkish Studies, Madison (WISC.), vol. 1, $\mathrm{n}^{\circ} 1$, pp. 102-113.

Heper M. (1987), Democracy and Local Government. Istanbul in the 1980's, Walkington (UK), Eothene Press 62 p. (IFEA: Obs Urb. 265)

Heper M. (1989), Local Government in Turkey. Governing Greater Istanbul, London, Routledge. (IFEA)

Heper M. (s.d.), Dilemmas of Decentralization. Municipal Government in Turkey, Friedrich Ebert Stiftung (Aus der Abteilung Entwicklungslander Forschung), Analysen $\mathrm{n}^{\circ}$ 123/124. (IFEA : Obs Urb. pp. 266-746)

3 Irmak Hüseyin (1999), Tarihe Yönelik Çalışmaların Yerel Yönetimlerde İmaja Etkisi (Kağıthane, Fatih), Yüksek Lisans Tezi, T.C.Marmara Üniversitesi Sosyal Bilimler Enstitüsü Halkla İlişkiler ve Tanıtım Ana Bilim Dalı, Halkla İlişkiler Bilim Dalı. (OUİ)

2000 Yılı Yatırım Programı, İstanbul Büyükşehir Belediyesi, 1999, 229 p. (OUI)

İnan Y. (1995), Türk Boğazlarının Siyasal ve Hukuksal Rejimi (régime politique et juridique des détroits turcs), Ankara, Turhan Kitabevi, 132 p.

İBB (1992), 2000'li Yıllara Hazırlanan İstanbul ve Dev Yatırımlar, İstanbul, İBşB, 104 p. (BÜ: NES- $\mathrm{n}^{\circ}$ 711. 4. İKS).

İstanbul Büyükşehir Belediyesi (1998), İstanbul Yeniden Yapılanıyor, İstanbul, 276 p.

İstanbul Büyükşehir Belediyesi, Mesken ve Gecekondu İşleri Müdürlüğü, (1998), 94/98 Faaliyet Raporu, 141 p. (ITTO: I. 11. P.)

İstanbul Büyükşehir Belediyesi (1999), İstanbul'un Altın Yılları 94/98, 4 Cilt, İstanbul. (İTO: I. 12. P. a, b, c, d.). (Obs Urb, 879-12/3-4)

İstanbul Külliyatı, Cumhuriyet Dönemi İstanbul İstatistikleri, 5; Seçim (1950-1995), İstanbul, İstanbul Büyükşehir Belediyesi, 1998. (OUI)

Iula-Emme \& T.C.Başbakanlık Toplu Konut İdaresi Başkanlığı (s.d.), Türkiye'de Yerel Yönetim Sisteminin Geliştirilmesi, İstanbul, $\mathrm{n}^{\circ}$ 1, 163 p.

Iula-Emme \& T.C.Başbakanlık Toplu Konut İdaresi Başkanlığı (s.d.), Yerel Yönetim Bankacılı̆̆

Iula-Emme \& T.C.Başbakanlık Toplu Konut İdaresi Başkanlığı (s.d.), Konut Politikaları ve Finansmanı, İstanbul, $\mathrm{n}^{\circ}$ 3, 119 p. 
Iula-Emme \& T.C.Başbakanlık Toplu Konut İdaresi Başkanlı̆̆ı (s.d.), Yerel Yönetim Yapiları, İstanbul, $\mathrm{n}^{\circ}$ 4, $112 \mathrm{p}$.

Iula-Emme \& T.C.Başbakanlık Toplu Konut İdaresi Başkanlığı (s.d.), Geleceğin İstanbul'u: Demokratik, Etkin ve İnsanca Yaşanabilir Bir Dünya Kenti, İstanbul, $n^{\circ} 5$.

Iula-Emme \& T.C.Başbakanlık Toplu Konut İdaresi Başkanlığg (s.d.), şehircilik ve Konut Bakanlı̆̆

Kılıçaslan İ. (1974), Büyük İstanbul şehrinde Hizmetler ve Belediye Giderleri Analizi Üzerine Bir Deneme, Doktora Tezi, İTÜ, Mimarlık Fakültesi, İstanbul, 129 p. (IFEA: Obs Urb. 190)

Köksal S. (1990),:İstanbul'daki Sosyal Demokrat Belediye Başkanları ve Gecekondu (les présidents socio-démocrates de la municipalité d'Istanbul et les gecekondu), İstanbul, TÜSES, Araştırmalar Vakfi, 67 p. (IFEA: Obs Urb. 260)

Özcan Ü. (1988), « Kent Yönetimi, Yöneticiler ve şehir Plancıları » (administration des villes, administrateurs et planificateurs), Planlama, 1988/2, pp. 3-5.

Özmucur C. (1976), « İstanbul İli Gelir Tahminleri 1950-1974 », BÜ Ekonomi Dergisi, vol. 4-5.

Öztürk a. (1997) 21. Yüzyıl Türkiyesi İçin Yerel Yönetim Modeli, İstanbul, Ümraniye Belediyesi Kültür Yayınları, 228 p. (IFEA).

Schüler H. (1998), Türkiye'de Sosyal Demokrasi. Particilik, Hemşehrilik, Alevilik, İstanbul, İletişim Yayınları, 346 p.

Sönmez M. (1999), « İstanbul Seçmeninin 50 Yıllık Tercihi », Birikim, n 123, Temmuz 1999, pp. 97-103.

Tuncay M. (1994), Kentsel Haklar, Karşılaştırmalı bir Çerçevede Türkiye, WALD/Dünya Yerel Yönetim ve Demokrasi Akademisi.

Uykucu K. E. (1979), İlçeleriyle Birlikte İstanbul, İstanbul, Kahraman Yayınları, 313 p. (BÜ: G. Coll. 915- 49618. UY61)

Ünlü H. (s.d.), Yerel Yönetimler Arası İşbirliği, Iula-Emme \& T.C.Başbakanlık Toplu Konut İdaresi Başkanlığı, İstanbul, $n^{\circ}$ 8, 93 p.

Ünlü H. (s.d.), Yönetimler Arası İlişkiler, Iula-Emme \& T.C.Başbakanlık Toplu Konut İdaresi Başkanlı̆̆ı, İstanbul, $\mathrm{n}^{\circ}$ 9, $110 \mathrm{p}$.

Yildırmı S. (1993), Local Government and Democracy, İstanbul, Iula-Emme \& T.C.Başbakanlık Toplu Konut İdaresi Başkanlı̆̆ı.

Yıldırım S. (s.d.), Yerel Yönetim ve Demokrasi, Iula-Emme \& T.C.Başbakanlık Toplu Konut İdaresi Başkanlığı, İstanbul, n 14, 200 p.

Yildırım S., Emrealp S. et alii (1988), Metropolitan Government in Istanbul, Istanbul: Metropolitan Municipality of Greater Istanbul and Iula-Emme.

1 Yıldırım S. \& Emrealp S. (s.d.), Başarının Yolları, Toplu Konut, Yerel Yönetimde, IulaEmme \& T.C.Başbakanlık Toplu Konut İdaresi Başkanlı̆̆ı, İstanbul, nº 1, 84 p.

Yücel A. (1994), Büyükşehir Yönetimi, İstanbul İçin Model ve İç Göçlerin Yönlendirilmesi, Ankara, DPT, Yapısal Uyum Sosyal Politikalar ve Koordinasyon Genel Müd., Planlama Dairesi, Mayıs 1994. 
53 Ziyaoğlu R. (1971), İstanbul Kadıları, şehreminleri, Belediye Reisleri ve Partiler Tarihi 1453-1971-İdarî- Siyasî, İstanbul, İ. Akgün Matbaası, 783 p. (IFEA: İst16) 